\title{
Geomorphic services for landslide risk evaluation in the RO-RISK Project
}

\author{
Dan Bălteanu, Marta Jurchescu, Mihaela Sima, Mihai Micu, Gheorghe Kucsicsa \\ Institute of Geography \\ Romanian Academy \\ Bucharest, Romania \\ igar@geoinst.ro,marta_jurchescu@yahoo.com
}

\begin{abstract}
The paper presents the steps undertaken within the RO-RISK (Disaster Risk Evaluation at National Level) project with the aim of achieving landslide hazard and risk evaluation at the national level, as well as the close interand transdisciplinary collaboration through the involvement of specialists and stakeholders during the whole research process, the results of which can be assigned to geomorphic services. A common methodology to analyze all the selected risks has been followed within the project, mainly focusing on hazard and impact analyses. At the end, three national and two local scale landslide scenarios have been analyzed into detail in order to provide risk figures as estimations on the location and magnitude of possible physical impacts on the population, the built-up environment and the transportation network, as well as economic and sociopsychological impacts, all of which were needed to finally estimate risk acceptability.
\end{abstract}

Keywords - landslides; risk assessment; geomorphic services; environmental changes; RO-RISK; Romania

\section{INTRODUCTION}

By engaging more and more in different projects, Geomorphology provides scientific services to decision makers and other relevant institutions in diverse fields such us civil protection, territorial planning and land management etc. These services are differentiated considering the spatial scale as well as the quality of the data and include geomorphological mapping and zoning, laboratory and field experiments, geomorphologic assessment using qualitative and quantitative methods and modeling.

The geomorphic services, together with climatic and ecosystem services, may provide support to increasing the resilience of society to extreme events, being suitable for economic assessment and for undertaking disaster management measures. The scientific services are based on a close inter- and transdisciplinary collaboration along with the involvement of specialists and stakeholders during the whole research process and include several steps: co-design (project structure, identification of the main issues), co-production (research stages followed by common analysis of the results and uncertainties) and results dissemination [1].

This study was developed in the framework of the RO-RISK project (2016) coordinated by the Romanian General Inspectorate for

Emergency Situations (GIES) and co-financed by the European Social Fund through the Operational Programme for Administrative Capacity (POCA).
In this context, through the geomorphological research on landslides undertaken within the RO-RISK project, synthesis data on landslide hazard and risk at national level have been produced as a support for the decisions undertaken by civil protection in managing this risk.

\section{THE RO-RISK PROJECT}

National risk assessment is considered by the European Commission a topic of highly importance and therefore became a conditionality for accessing European Funds in the 2014-2020 time period. In order to comply with this conditionality, the RO-RISK (Disaster Risk Evaluation at National Level) project was undertaken in 2016, being coordinated by the General Inspectorate for Emergency Situations (GIES, at the same time the main stakeholder) and co-financed by the UE through the European Social Fund in the frame of the Operational Program Administrative Capacity 2014 - 2020.

Developed as such, the project aimed to provide a framework for the risk assessment process in Romania, thus contributing to strengthening risk prevention and management in the country. It focused on assessing the specific hazards and risks occurring on the Romanian territory. In order to ensure a proper identification of risks having major impact at national level and their integrated management, research and consultation activities have been undertaken, before the start of the actual assessments, to set out a common language base and a coherent and unitary frame for the analyses. The resulting methodology for risk evaluations and integration of individual risk assessments [2] was constantly subject to improvements during the projects' implementation as risk assessment activities were advancing.

The project identified 10 types of hazards and risks significant for the national security. Therefore, scientific evaluations performed in the frame of the project, by research institutes as well as central administration institutions, have been concentrated on: floods, drought, forest fires, landslides (slides), earthquakes, nuclear and radiological accidents, Seveso accidents, major accidents involving dangerous substances, epidemics, animal epidemics and zoonosis. Besides research, the project also 
included consultation activities with various stakeholders involved in risk management and assessment [3].

\section{THE PROCESS OF LANDSLIDE RISK ASSESSMENT AND MANAGEMENT}

The majority of landslide studies are conducted with the final goal of providing risk estimation, i.e. a measure of the expected losses due to landslide hazard. Estimated levels of risk can subsequently be subjected to evaluation through a cost-benefit analysis which would differentiate among intolerable, tolerable and acceptable risks. The risk treatment phase requires comparisons with other risks, discussions and evaluation of treatment options, also including cost-benefit analyses of proposed risk treatment measures. This entire process, comprising the abovementioned successive phases and concluding with the implementation of policies and measures for risk reduction, is known as risk management.

The landslide risk component of the RO-RISK project, as was the case for every project component dedicated to the evaluation of one individual risk, was overall structured according to the main stages making up the risk management process. The landslide (slide) risk estimation is based on integrating two major factors referring to the probability patterns (hazard analysis), the identification of the elements at risk and their vulnerability (impact analysis), according to the well-known formula [4]:

\section{Risk $=$ hazard $\times$ vulnerability $\times$ elements at risk}

In the initial, scoping phase of the co-design process, numerous discussions among experts and the main stakeholder took place, concerning the selection of the optimal methodology to be employed throughout the project, the resources needed as well as the level of detail for the analysis. Following these and aiming to provide scientific assessments for the main components of the landslide risk management process, framing methodologies were adopted, respecting international recommendations in the field, and adapted, on the one hand, to the specific morpho-structural, climatic and socio-economic environment and, on the other hand, to the available resources. This was the first complete approach of this kind to be undertaken at a national scale in Romania, after the elaboration of the country's landslide susceptibility map [5].

As required, an important stage was dedicated to analyzing the hazard, i.e. the probability of occurrence of a damaging landslide of a given magnitude. Research focused on separately assessing the spatial probability, given by the terrain predisposing conditions, the temporal frequency and the magnitude of such processes.

Landslides respond either fast or delayed to triggers like precipitation, earthquakes, fluvial erosion or human interventions in the environment. During the last two centuries, several events were responsible for initiating a large numbers of landslide processes, e.g. the large earthquakes of 1809 and $1838(\mathrm{M}=7.5-7.9)$, the moderntime earthquakes of 1940 (M 7.7) and 1977 (M 7.4), the rainy period of 1968-1974, the wet seasons of 2004, 2005, 2006 and 2010 [3, 6, 7]. As for the relationship between landslide typology and major triggers (precipitation, earthquakes), there's a rather incomplete correlation of parallel inventories, which cannot support, for the moment, typological specifically-addressed susceptibility/hazard maps. However, the available information allows some empiric correlations: low magnitude earthquakes $\left(M_{w} 4-5\right)$ are likely to trigger rock falls, disrupted debris and earth slides, while an increase of magnitude (above $\mathrm{M}_{\mathrm{w}}$ 6-7) can lead to a shift towards rock slumps, rock block slides and earth flows [8,9]. The spring showers are triggering both shallow earth slides and medium-to-deep seated (when overlapping snowmelt) complex/compound landslides, while torrential summer precipitation are responsible for earth/debris flow pulsations.

A large number of landslide hazards scenarios (40) were constructed based on the previous analysis of spatiotemporal relationships among the most relevant predisposing, preparatory and triggering factors. As part of the climatic factors, precipitation was selected as having the most important landslide triggering role, which lead to elaborating 34 rainfall-induced scenarios. Relevant climatic parameters were considered and statistically computed: maximum seasonal rainfall, maximum $72 \mathrm{~h}-$ rainfall and extreme length of wet intervals with different return periods [10]. Earthquakes are widely considered another important landslide triggering factors. Among the numerous seismic regions of Romania, Vrancea intermediate acts as the most active one, with documented effects for several earthquakes. Based on these considerations, 4 earthquake-induced landslides hazards were also evaluated through deterministic (reproducing the Vrancea intermediate recent major earthquakes of 1940 and 1977) and probabilistic approaches. The trigger indicators' maps, displaying the distribution of either extreme precipitation amounts or peak ground acceleration (PGA) values, were overlaid with the susceptibility map following an expert-judgment approach, producing hazard classifications.

Not only current conditions but also possible future environmental changes were considered in obtaining the various hazard scenarios. In case of the climatic factors, possible future evolutions were accounted for on the basis of climatic projections for the periods 2021-2050 according to IPCC climate change scenarios (RCPs 4.5 and 8.5) and selected EURO-CORDEX regional climate models [10]. In the construction of landslide hazard scenarios, spatial data on future dynamics of land use/land cover (year 2050) were also considered, being modeled by CLUE-S (the Conversion of Land Use and its Effects at Small regional extent), a model that allows to simulate land use/land cover changes using diverse development scenarios [11]. In the RO-RISK project, the Corine Land Cover database together with physiographic and socioeconomic data have been used to generate 31 causal factors for change, grouped within the main land use/land cover simulation categories.

The further in-depth analysis required a selection of three national-coverage scenarios based on pre-imposed prioritization criteria of likelihood and severe potential impacts. These were described into more detail with the purpose of identifying information on the environment, the population and the human and economic assets existing in the hazard-threatened areas. Additionally, two local-scale scenarios basing on different methodologies 
have been designed and subsequently analyzed into detail, following the project's methodological flow.

The analysis of elements at risk was undertaken at the level of LAU2 units for several indicators as: demography (total population and population density); number of residential buildings; main land use/land cover categories; protected areas; transport infrastructure (lengths of roads and railways); public utility network (water and heating supplies). Hazard exposure has been assessed by quantifying the elements at risk for the high and very high hazard classes in case of the selected 10-year and 100-year national scenarios.

Three impact types and 17 impact criteria were investigated within the project for each individual risk, in order to allow for subsequent comparisons among risks: physical (loss of life, persons injured, evacuated and without access to essential services, affected buildings, transportation networks, lifelines, response means, protected areas and other affected areas), economical (costs associated to human losses, material and environmental damages, emergency response forces, indirect costs), social and psychological impacts (interruption of daily life, societal psychological impact). The same descriptors were used to express these impacts for the various risks, being preimposed through the established methodology [2]. Estimation of vulnerability was therefore subordinated to the requested impact assessments. Landslide vulnerability was addressed through integrating the approaches used in social and climate-change related sciences as well as in natural sciences. This allowed to develop several assessment steps: i) estimation of an intrinsic vulnerability; ii) identification of a hazard-specific vulnerability and, finally, iii) quantification of the expected degree of loss using recent historical information on landslides-induced damages [12]. The latter step enabled to compute first estimations on the location and magnitude of possible physical impacts on population, the built-up environment and the transportation network.

Collaborations with other institutions in the field of economics and social sciences permitted data sharing and transfer, the physical impact estimates forming the input to further evaluations regarding the economic and the social and psychological impacts. Finally, all impact criteria were combined in order to derive a global impact for each selected scenario.

\section{GEOMORPHIC SERVICES PROVIDED BY RO-RISK}

Scientific services are increasingly recognized as a way to transfer knowledge to end-users, constituting the necessary link between science and practitioners.

The work, aimed at evaluating the landslide risk in the framework of the RO-RISK project, proposes several scientific services in each stage of the analysis.

Landslide zonation maps were elaborated, allowing the identification, across the national territory, of hotspot areas in terms of terrain susceptibility, hazard, elements at risk, exposure, vulnerability, impact and risk, and being associated to different present-day or future conditions.

As mentioned above, in the course of the assessment process also future environmental evolutions were taken into account. Consequently, trends in the spatial distribution and levels of landslide hazard and risk could be identified for different time horizons (up to 2050) as a response to land-use and climate changes.

Evaluation and calibration/validation of results is considered essential prior to delivering the outcomes in the form of scientific services. In the landslide component of the RO-RISK project, this was achieved by means of expert knowledge. In this sense, a strong collaboration was undertaken with specialists from the Babeş-Bolyai University in Cluj-Napoca and the "Alexandru Ioan Cuza" University of Iaşi, who provided the necessary knowledge on regional aspects.

Computed impacts and likelihoods values associated to the priority landslide scenarios were synthesized and placed on risk matrices designed to allow for comparisons with the other natural and technological risk scenarios.

The shaping of geomorphic services was based on a strong collaboration with the main beneficiary of the project, GIES. In this respect the main results were continuously tailored to its specific needs and requirements. As an example, one requirement for risk evaluation was to identify the degree of risk tolerance based on a standard scale proposed by the beneficiary and based on thresholds for impact and likelihood.

One major outcome of the project, namely the evaluation maps, have been disseminated though a webplatform where all individual risk assessment results were brought together and put into a standard format in order to be comparable.

\section{CONCLUSIONS}

Slope instability in Romania is believed to have increased in the recent period due to a general degradation of management works (after 1990), climate change and human pressure on the environment (e.g. deforestation).

The RO-RISK project provided a first scientific basis for the national level assessment of natural and technological risks including landslides and is intended to be continued and improved. Such an assessment should be meant to function as a support for proposing risk treatment options and plans and providing capacity building for national and local authorities. Results achieved in the field of landslides are expected to serve a national integrated disaster management planning, at the same time indicating where more detailed assessments would be needed. Given the scale at which the evaluations were conceived, attention is drawn to the fact that outcomes are not meant to be used for regional development or local land planning, management of existing or proposed transportation or utility infrastructures, the development of engineering works etc.

In spite of the several calibrations and corrections provided by the inclusion of expert judgment during the different stages involved in the risk evaluation, several uncertainties were recognized as affecting the outcomes. The most significant ones emerge from the degree of data availability and access and the very limited time allocated to the project. The main aspects which could contribute to reducing uncertainties in future assessments include: improving databases and existing landslide inventories as well as harmonizing these and establishing observational 
and monitoring sites for different landslides types in various natural and human-affected environments.

For a proper functioning, scientific services require a stronger connection with the stakeholders from the very start of the project idea, to better understand the beneficiary needs, the practical utility and the expectations regarding the final products. This might be more time consuming but it finally ensures a better quality and applicability of the results. A stronger communication from both sides would enable stakeholders to gain experience in being involved in scientific projects and be aware of the research particularities, and scientists to gain more insights into the real needs and the practical use of their outputs.

\section{ACKNOWLEDGMENT}

The authors wish to thank the coordinating institution and main beneficiary of the project, GIES, and particularly Col. Dr. Francisc Senzaconi, for the good collaboration and the continuous support throughout the project's development, as well as the partner institutions involved in the landslide research: the Technical University of Civil Engineering (UTCB), the National Institute for Research and Development in Constructions, Urban Planning and Sustainable Spatial Development (URBAN-INCERC), the National Institute for Earth's Physics (NIEP) and the National Meteorological Administration (ANM). The study also benefitted from the scientific inputs of Prof. Dănuţ Petrea, Dr. Ştefan Bilaşco (Babeş-Bolyai University, Cluj-Napoca) and Dr. Ciprian Mărgărint ("Alexandru Ioan Cuza" University of Iaşi). The authors appreciate the fruitful collaborations with the Institute of Sociology and the Institute for Economic Forecasting of the Romanian Academy. The entire team of personnel involved in the different parts of the project's assessment is also thanked.

\section{REFERENCES}

[1] W. Mauser, G. Klepper, M. Rice, B.S. Schmalzbauer, H. Hackmann, R. Leemans, and H. Moore, "Transdisciplinary global change research: the co-creation of knowledge for sustainability", Curr. Opin. in Environ. Sustain., vol. 5, no. 3-4, pp. 420-43, 2013.

[2] GIES, "Methodology for risk evaluation and integration of individual risk assessments" ("Metodologia de evaluare a riscurilor si de integrare a evaluărilor de risc sectoriale”),
https://www.igsu.ro/documente/RORISK/Metodologia\%20de\%20evaluare\%20unitara\%20a\%20riscuri lor\%20-\%20versiune\%20finala.pdf, 2016, last accessed April 2017.

[3] GIES, “Country report 5.1 Conditionality. Romania 2016”, https://www.igsu.ro/documente/RORISK/Raport_Final_de_tara.pdf”, 2016, last accessed April 2017.

[4] M.J. Crozier and T. Glade "Landslide hazard and risk: issues, concepts and approach” in Landslide hazard and risk, vol. III, T. Glade, M. Anderson and M.J. Crozier, Eds. Chichester: John Wiley \& Sons, 2005, pp. 1-40.

[5] D. Bălteanu, V. Chendes, M. Sima, and P. Enciu "A country-wide spatial assessment of landslide susceptibility in Romania", Geomorph., vol. 124, no. 3-4, pp. 102-112, 2010.

[6] NIEP, "ROMPLUS Catalogue” (“Catalog ROMPLUS”), http://www.infp.ro/romplus/, 2017, last accessed April 2017

[7] C.S. Dragotă, Precipitațiile excedentare în România. București: Edit. Academiei Române, 2006. (in Romanian)

[8] D.K. Keefer, "Investigating landslides caused by earthquakes - a historical review”, Surv. Geophys., vol. 23, pp. 473-510, 2011.

[9] V. Del Gaudio and J. Wasowski, “Advances and problems in understanding the seismic response of potentially unstable slopes”, Eng. Geol., vol. 122, pp. 73-83, 2011.

[10] M. Jurchescu, D. Micu, M. Sima, D. Bălteanu, C. Dragotă, M. Micu, "An approach to investigate the effects of climate change on landslide hazard at national scale (Romania)”, in Proceedings of the Romanian Geomorphology Symposium, 33d ed., 11-14 May, 2017, Iași, M. Niculiță and M.C. Mărgărint, eds., pp. 121-124.

[11] P.H. Verburg, W. Soepboer, R. Limpiador, M.V.O. Espaldon, M. Sharifa, and A. Veldkamp, "Land use change modelling at the regional scale: the CLUE-S model”, Environ. Manag., vol. 30, pp. 391-405, 2002.

[12] M. Jurchescu et al., unpublished. 